\title{
Radiation Effects on Polyacetylenes Having Substituents
}

\author{
Toshinobu Higashimura, Ben-Zhong TANG, Toshio Masuda, \\ Hitoshi YAMAOKA, ${ }^{*}$ and Tomochika MATSUYAMA* \\ Department of Polymer Chemistry, Kyoto University, \\ Kyoto 606, Japan \\ * Research Reactor Institute, Kyoto University, \\ Kumatori, Osaka 590-04, Japan
}

(Received June 12, 1984)

\begin{abstract}
Effects of $\gamma$-ray irradiation on high molecular weight polyacetylenes with various substituents were studied in air and in vacuum. The molecular weights of polymers from aliphatic disubstituted acetylenes (2-octyne and 2-decyne) remarkably reduced with irradiation in air. Their $G$ values for chain scission in air were as high as $3-12$, whereas no degradation occurred in vacuum. The degraded polymers contain carbonyl and hydroxyl groups, and are soluble in polar solvents such as methyl ethyl ketone and acetone. In contrast, polymers of aromatic disubstituted acetylenes (1-phenyl-1-propyne and 1-chloro-2-phenylacetylene) hardly degraded in air even with irradiation up to $40 \mathrm{Mrad}$. The degradation behavior of poly( $t$-butylacetylene) was intermediate between those of the above aliphatic and aromatic polymers. Thus the radiolysis of polyacetylenes was found to be greatly dependent on the kind of substituents.

KEY WORDS Substituted Acetylene / Poly(2-octyne) / Poly(t-butylacetylene) / Poly(1-phenyl-1-propyne) / Radiation Effect / Degradation / Oxidation / $G$ Value /
\end{abstract}

The polymers obtained from substituted acetylenes are expected to show unique properties such as electrical conductivity and chemical reactivity of the backbone, since they contain alternating double bonds in the main chain as well as polyacetylene. In comparison with wide-ranging investigations on polyacetylene, however, little work has been done on polymers of substituted acetylenes because of difficulties in the synthesis of high molecular weight polymers.

In a series of our recent studies, ${ }^{1}$ we have succeeded in producing high polymers from acetylenes having bulky substituents by use of transition metal catalysts. It has recently revealed that the polymers thus obtained show excellent physical properties such as gas permeability ${ }^{2,3}$ and photoconductivity. ${ }^{4}$

Extensive studies on the thermal oxidation of polyacetylene have been carried out in order to clarify the changes in various physical properties and mechanism of oxidation. ${ }^{5}$ On the other hand, the reactions of polymers of substituted acetylenes induced by heating or by the action of ionizing radiation have scarcely been investigated so far, although a few studies on polypropyne ${ }^{6}$ and polyphenylacetylene $^{7}$ were reported.

In the present paper, the radiation effects on aliphatic and aromatic polyacetylenes with bulky substitutents have been studied. These polymers are expected to be more reactive than the corresponding vinyl polymers due to the presence of double bonds in the backbone structure. In fact, polymers of aliphatic disubstituted acetylenes [poly(2-octyne) and poly(2-decyne)] were found to degrade easily in air with an exposure of $\gamma$-rays, suggesting 
that these polymers are applicable to new materials for electron beam resists.

\section{EXPERIMENTAL}

\section{Polymer Samples}

Three aliphatic acetylenes $\left(\mathrm{CH}_{3} \mathrm{C} \equiv \mathrm{C}-n \mathrm{C}_{5}\right.$ $\left.\mathrm{H}_{11},{ }^{8} \mathrm{CH}_{3} \mathrm{C} \equiv \mathrm{C}-n \mathrm{C}_{7} \mathrm{H}_{15},{ }^{8} \mathrm{HC} \equiv \mathrm{C}-t \mathrm{Bu}^{9}\right)$ and two aromatic acetylenes $\left(\mathrm{CH}_{3} \mathrm{C} \equiv \mathrm{CPh},{ }^{10} \mathrm{ClC} \equiv\right.$ $\mathrm{CPh}^{11}$ ) were polymerized with catalysts suitable to obtain high molecular weight polymers. The polymerizations were carried out under dry nitrogen and the formed polymers were purified as described before. ${ }^{9-11}$ As shown in Table I, the molecular weights of the polymers are $6 \times 10^{4}-24 \times 10^{4}$. Polymer films were prepared by casting toluene solutions of polymers on a glass plate at room temperature (film thickness $c a .0 .1 \mathrm{~mm}$ ).

\section{Procedures}

Polymers were irradiated at $c a .60^{\circ} \mathrm{C}$ by using a ${ }^{60} \mathrm{Co} \gamma$-ray source of $7000 \mathrm{Ci}$. Irradiations in air were performed in open glass tubes. For irradiations in vacuum, samples in glass ampoules were sealed off after complete degassing. Irradiated polymers were immediately dissolved in tetrahydrofuran, and their molecular weight distributions (MWD) were observed by gel permeation chromatography (GPC) on a JASCO Triroter chromatograph (column, Shodex A802, A804, A806 (polystyrene gel); eluent, tetrahydrofuran). Number- and weight-average molecular weights
( $M_{n}$ and $M_{w}$, respectively) of polymers were calculated based on a polystyrene calibration. IR spectra of polymers were recorded on a Shimadzu IR435 spectrophotometer.

\section{RESULTS}

\section{Substituent Effects on $\gamma$-Ray Radiolysis of Polymers}

To clarify influences of substituents on the radiolysis of polymers, films (thickness $c a$. $0.1 \mathrm{~mm}$ ) of the five different polymers shown in Table I were irradiated in air with $\gamma$-rays at the total dose of $40 \mathrm{Mrad}$. In consequence, the polymers from $t$-butylacetylene $(\mathrm{HC} \equiv \mathrm{C} t \mathrm{Bu})$ and aromatic acetylenes $\left(\mathrm{CH}_{3} \mathrm{C} \equiv \mathrm{CPh}, \mathrm{ClC} \equiv\right.$ $\mathrm{CPh})$ retained their original form after the irradiation, whereas both poly(2-alkynes) changed into greases.

The molecular weights of polymers were calculated from their GPC curves, and are summarized in Table II. Figure 1 shows the MWD curves (GPC charts) for three representative polymers before and after the irradiation. The molecular weight of poly(2octyne) decreased remarkably by the irradiation, and the degradation product contained no high molecular weight fraction. Poly(2decyne), another poly(2-alkyne), degraded just in the same way as poly(2-octyne). In contrast, poly(1-phenyl-1-propyne) virtually maintained its high molecular weight after the $\gamma$-ray irradiation of $40 \mathrm{Mrad}$. Poly(1-chloro-2-phenylacetylene), which has chlorine in place of the

Table I. Polymerization of substituted acetylenes having bulky groups ${ }^{\mathrm{a}}$

\begin{tabular}{|c|c|c|c|c|}
\hline \multirow{2}{*}{ Monomer } & \multirow{2}{*}{ Catalyst } & \multirow{2}{*}{$\frac{\text { Temp }}{{ }^{\circ} \mathrm{C}}$} & \multirow{2}{*}{$\begin{array}{r}M_{n} \\
10^{4}\end{array}$} & \multirow{2}{*}{ Ref } \\
\hline & & & & \\
\hline $\mathrm{CH}_{3} \mathrm{C} \equiv \mathrm{C}-n \mathrm{C}_{5} \mathrm{H}_{11}$ & $\mathrm{MoCl}_{5} \cdot \mathrm{Ph}_{4} \mathrm{Sn}$ & 30 & 8.4 & 8 \\
\hline $\mathrm{CH}_{3} \mathrm{C} \equiv \mathrm{C}-n \mathrm{C}_{7} \mathrm{H}_{15}$ & $\mathrm{MoCl}_{5} \cdot \mathrm{Ph}_{4} \mathrm{Sn}$ & 30 & 6.1 & 8 \\
\hline $\mathrm{HC} \equiv \mathrm{C}-t \mathrm{Bu}$ & $\mathrm{MoCl}_{5}$ & 30 & 22 & 9 \\
\hline $\mathrm{CH}_{3} \mathrm{C} \equiv \mathrm{CPh}$ & $\mathrm{TaBr}_{5}$ & 80 & 24 & 10 \\
\hline $\mathrm{ClC} \equiv \mathrm{CPh}$ & $\mathrm{Mo}(\mathrm{CO})_{6}-\mathrm{CCl}_{4}-h v$ & 30 & 18 & 11 \\
\hline
\end{tabular}

${ }^{\mathrm{a}}[\mathrm{M}]_{0}=0.50-1.0 \mathrm{M}$, in toluene (in $\mathrm{CCl}_{4}$ for $\mathrm{ClC} \equiv \mathrm{CPh}$ ). 


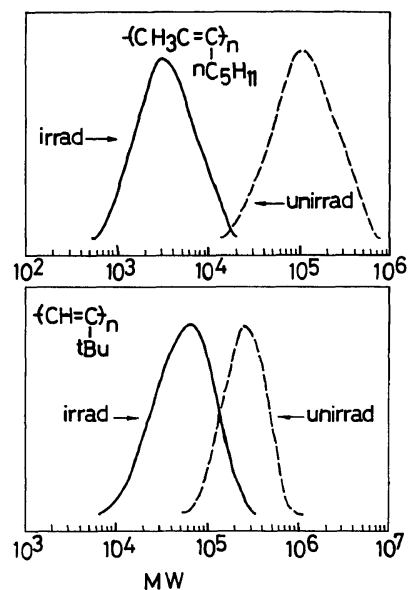

Table II. Radiation effect on polymers of substituted acetylenes ${ }^{\mathrm{a}}$

\begin{tabular}{|c|c|c|c|c|}
\hline \multirow[b]{2}{*}{ Polymer } & \multicolumn{2}{|c|}{$\begin{array}{c}\text { Before } \\
\text { irradiation }\end{array}$} & \multicolumn{2}{|c|}{$\begin{array}{c}\text { After } \\
\text { irradiation }\end{array}$} \\
\hline & $M_{n} / 10^{4}$ & $M_{w} / M_{n}$ & $M_{n} / 10^{4}$ & $M_{w} / M_{n}$ \\
\hline $\begin{array}{rl}(\mathrm{C}= & =\mathrm{C} \\
\mathrm{CH}_{3} & n \mathrm{C}_{5} \mathrm{H}_{11}\end{array}$ & 8.4 & 2.1 & 0.25 & 3.2 \\
\hline 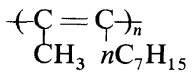 & 6.1 & 1.9 & 0.21 & 2.8 \\
\hline$\left(-\mathrm{C}=\underset{t}{\mathrm{C}-)_{n}}\right.$ & 22 & 1.3 & 4.1 & 1.7 \\
\hline $\begin{array}{c}\left(\mathrm{C}=\mathrm{C}_{\mathrm{C}}^{\mathrm{C}}\right)_{n} \\
\mathrm{CH}_{3} \mathrm{Ph}\end{array}$ & 24 & 1.3 & 16 & 1.5 \\
\hline$\underset{\mathrm{Cl}}{(\mathrm{C}}=\underset{\mathrm{Ph}}{\mathrm{C}})^{{ }_{n}}$ & 18 & 1.4 & 13 & 1.4 \\
\hline
\end{tabular}

a Dose rate $2.20 \mathrm{Mrad} \mathrm{h}^{-1}$, total dose $40.4 \mathrm{Mrad}$, in air, $60^{\circ} \mathrm{C}$, filmy sample.

methyl group in poly(1-phenyl-1-propyne), behaved in a similar manner. These findings indicate that polymers of aromatic disubstituted acetylenes are sufficiently stable to radiation. The stability of poly( $t$-butylacetylene) to radiation was intermediate between those of the above aliphatic and aromatic polyacetylenes.

Thus, it has proved that not only the bulkiness but also the kind of substituents greatly affects the degradability of polymers.

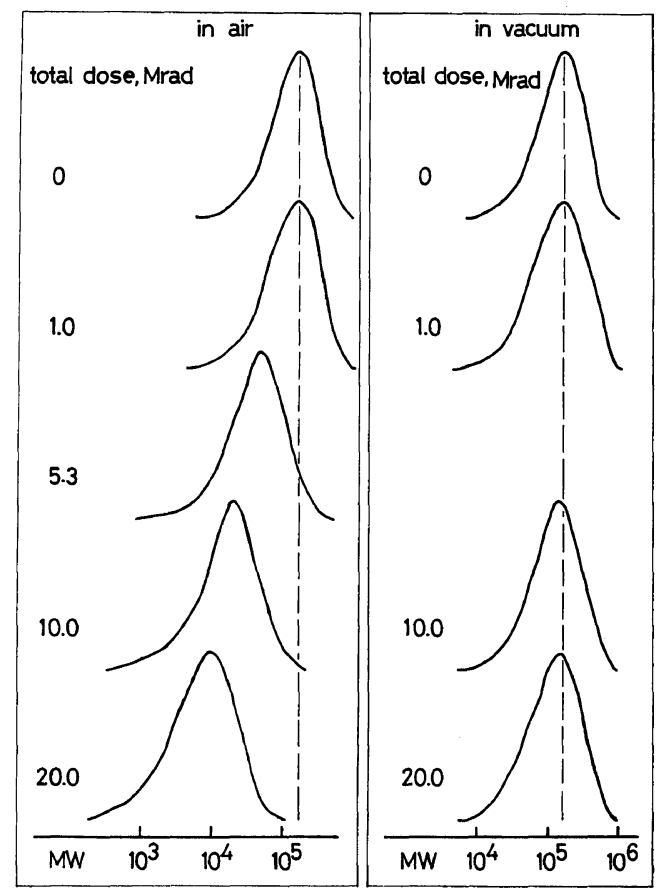

Figure 2. Effect of $\gamma$-ray irradiation on the molecular weight of poly(2-octyne); $60^{\circ} \mathrm{C}$, filmy sample.

\section{$\gamma$-Ray Radiolysis of Poly(2-octyne)}

It has become clear that poly(2-alkyne)s readily undergo $\gamma$-ray radiolysis in air. Therefore, the degradation behavior of poly(2-octyne) was studied in more detail.

Figure 2 shows the dose dependence of MWD (GPC charts) in the radiolysis of filmy 
poly(2-octyne). Upon irradiation in air, the peak in the MWD curve shifted to lower molecular-weight with increasing total dose. A feature of this degradation is that the high molecular weight fraction completely disappears. On the other hand, the peak in the MWD curve hardly moved irrespective of total dose, when the polymer was irradiated in vacuum.

The relationships between radiation dose and the molecular weight calculated from the MWD curves of Figure 2 are shown in Figure 3. The values in parentheses in the Figure are dispersity ratios of $M_{w}$ to $M_{n}\left(M_{w} / M_{n}\right)$. The $M_{n}$ of polymers irradiated in air decreased in an exponential way with increasing total dose, while $M_{w} / M_{n}$ somewhat increased. In contrast, both $M_{n}$ and $M_{w} / M_{n}$ scarcely changed upon irradiation in vacuum $\left(M_{n}\right.$ increased slightly at a low dose). These results lead to a conclusion that oxygen is essential to the $\gamma$-ray radiolysis of poly(2-octyne) (incidentally, poly(2-octyne) is stable enough in air at room temperature over a period of several months if kept in the dark).

Figures 4 and 5 show changes in the IR spectrum and in weight, respectively, with the powdery polymer irradiated in air. With increasing radiation dose, the absorption at 1750 and $1720 \mathrm{~cm}^{-1}$ due to carbonyl groups appeared and increased. A band at $3425 \mathrm{~cm}^{-1}$ probably due to hydroxyl group also appeared in the sample exposed to higher dose. As seen in Figure 5, the polymer weight increased approximately in proportion to total dose less than $20 \mathrm{Mrad}$. This is attributed to the formation of carbonyl and hydroxyl groups by reaction of the polymer with oxygen in air. This is confirmed by IR spectroscopy. On irradiation over $20 \mathrm{Mrad}$, the polymer weight tends to decrease with increasing total dose, indicating the occurrence of decomposition.

Interestingly, the solubility of the poly(2octyne) irradiated in air becomes different from that of the pristine polymer owing to the formation of polar groups and the reduction of

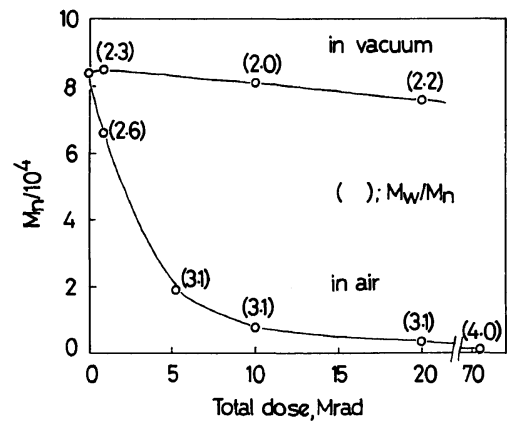

Figure 3. Effect of irradiation dose on $M_{n}$ and $M_{w} / M_{n}$ of poly(2-octyne) (before irradiation: $M_{n}=8.4 \times 10^{4}$, $\left.M_{w} / M_{n}=2.1\right) ; 60^{\circ} \mathrm{C}$, filmy sample.

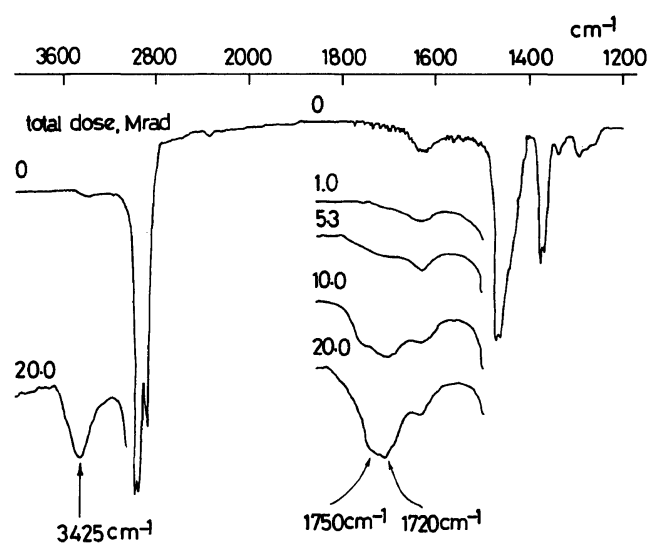

Figure 4. IR spectra of poly(2-octyne) irradiated in air at $60^{\circ} \mathrm{C}$.

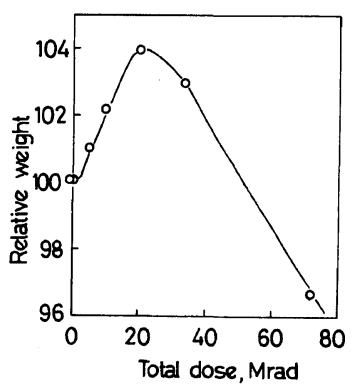

Figure 5. Weight change of poly(2-octyne) by irradiation in air at $60^{\circ} \mathrm{C}$.

molecular weight (see Table III). That is, polymer samples irradiated with high doses easily dissolve in methyl ethyl ketone and acetone which are nonsolvents of poly(2-octyne). On the other hand, when a film of 
Table III. Solubility of poly(2-octyne) irradiated in air $^{\mathrm{a}}$

\begin{tabular}{cccccc}
\hline Total dose & \multicolumn{4}{c}{ Solubility } \\
\cline { 1 - 5 } \cline { 3 - 5 } Mrad & & $\begin{array}{c}\text { Tetra- } \\
\text { hydro- } \\
\text { furan }\end{array}$ & $\begin{array}{c}\text { Methyl } \\
\text { ethyl } \\
\text { ketone }\end{array}$ & Acetone & Methanol \\
\hline 0 & S & I & I & I \\
5 & S & I & I & I \\
10 & S & SW & I & I \\
20 & S & S & I & I \\
40 & S & S & S & I \\
\hline
\end{tabular}

a $\mathrm{S}$, soluble; Sw, swollen; I, insoluble.

poly(2-octyne) was irradiated in vacuum, the solubility of the polymer did not change, but a small amount of insoluble fraction formed.

\section{$G$ Values for Main Chain Scission}

In order to estimate the efficiency of degradation on poly(2-octyne), $G$ values for main chain scission $\left(G_{\mathrm{s}}\right)$, which are the number of scission per $100 \mathrm{eV}$ of absorbed dose, were calculated from the results of GPC measurements. The $G_{\mathrm{s}}$ values at different absorbed doses are listed in Table IV. The $G_{\mathrm{s}}$ values in the irradiation doses beyond $10 \mathrm{Mrad}$ are almost constant at around 10 over the wide range of absorbed doses, although those in the initial stage of irradiation are rather small.

The $G_{\mathrm{s}}$ values for other polymers obtained from the results of Table II are as follows: $G_{\mathrm{s}}$ [Poly(2-decyne)] 11.3, $G_{\mathrm{s}}$ [Poly( $t$-butylacetylene)] 0.49, $G_{\mathrm{s}}$ [Poly(1-phenyl-1-propyne)] 0.05, and $G_{\mathrm{s}}[\mathrm{Poly}$ (1-chloro-2-phenylacetylene) $] 0.06$.

\section{DISCUSSION}

\section{Reaction Mechanism of Degradation}

Based on the experimental results, the following elementary processes would be considered as one of the most probable degradation mechanisms on irradiated polymers of substituted acetylenes, although various reaction schemes can be supposed:<smiles>[R]CC(C)=C(C)C(C[R])(C[R])C(C[R])=C(C)CCC(C[R])=C(C)C(C[R])C(C)C(C[R])=C(C)C</smiles>

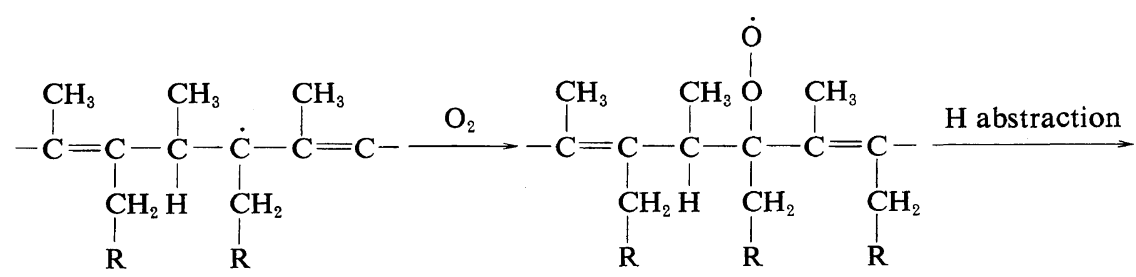<smiles>[R]CC(C)C(C)(C)C(C)(OO)C(C)(C[R])C(C)C</smiles>

In aromatic polyacetylenes, the radical formed initially by irradiation are stable due to delocalization of the energy absorbed, and<smiles>[R]CC(=C)C(C)(O)[NH2+]C(=O)C[R]</smiles>

the resulting peroxy radicals do not possess an ability of hydrogen abstraction from phenyl groups because of higher bonding energy of 
Table IV. Changes in molecular weight of irradiated poly(2-octyne) and $G$ values for chain scission $\left(G_{\mathrm{s}}\right)^{\mathrm{a}}$

\begin{tabular}{ccccc}
\hline Total dose & & \multicolumn{2}{c}{$M_{w}$} & $G_{\mathrm{s}}$ \\
\cline { 1 - 1 } Mrad & & $M_{n}$ & $M_{n}$ & \\
\hline 0 & & 84000 & 2.1 & - \\
1.0 & 66000 & 2.6 & 3.3 \\
5.3 & 19000 & 3.1 & 7.6 \\
10.0 & 8000 & 3.1 & 11.2 \\
20.0 & 3800 & 3.1 & 12.5 \\
72.6 & 1100 & 4.0 & 12.2 \\
\hline
\end{tabular}

${ }^{\text {a }}$ Dose rate $2.03 \mathrm{Mrad} \mathrm{h}^{-1}$, in air, $60^{\circ} \mathrm{C}$.

aromatic hydrogens. In addition, the hydrogen transfer occurring at the chain scission is only possible in the case of polymers having alkyl substituents. The lower reactivity of poly $(t-$ butylacetylene) would be responsible for the absence of allyl hydrogen in the substituent. The factors mentioned above may result in the remarkable difference of degradation behavior between aliphatic polyacetylenes and aromatic ones. Further experiments including the identification of degradation products will be required to explain the present interesting observation.

\section{Comparison of $G_{\mathrm{s}}$ Values}

$G_{\mathrm{s}}$ values for poly(methyl methacrylate), which is well known as a typical radiationdegradable polymer, have been reported to be $1.8-3.7$ in vacuum. ${ }^{12-15}$ These values slightly decreased in the presence of air. ${ }^{12,13} G_{\mathrm{s}}$ values for polyisobutene have been found to be 2.8 5.0 in vacuum ${ }^{16-18}$ and to be independent of the presence of air. ${ }^{17}$

In the case of poly(2-octyne), on the other hand, the degradation scarcely occurred in vacuum, whereas the quite higher $G_{\mathrm{s}}$ value was observed in the presence of air. This marked effect of oxygen on the degradation would be attributed to the presence of reactive double bonds in the backbone structure of the polymer.

In conclusion, it has been clarified that the polymers of aliphatic disubstituted acetylenes irradiated in air are more degradable than degradation-type vinyl polymers, and also that there exists remarkable difference in the solubility of the polymers before and after irradiation. Therefore, it will be worthwhile that these polymers are further investigated in the application for new materials of electron-beam resists.

Acknowledgment. This research was partly supported by a Grant-in-Aid for Scientific Research from the Ministry of Education, Science and Culture (No. 58470088).

\section{REFERENCES}

1. For a review, see: T. Masuda and T. Higashimura, Acc. Chem. Res., 17, 51 (1984).

2. T. Higashimura, T. Masuda, and M. Okada, Polym. Bull., 10, 114 (1983)

3. T. Masuda, E. Isobe, T. Higashimura, and K. Takada, J. Am. Chem. Soc., 105, 7473 (1983).

4. E. T. Kang, P. Ehrlich, A. P. Bhatt, and W. A. Anderson, Appl. Phys. Lett., 41, 1136 (1982); Polym. Prepr., Am. Chem. Soc.. Div. Poly. Chem., 24(2), 73 (1983).

5. As a recent study, F. G. Will and D. W. McKee, $J$. Polym. Sci., Polym. Chem. Ed., 21, 3479 (1983). See also references cited therein.

6. J. C. W. Chien, L. C. Dickinson, and X.-Z. Yang, Macromolecules, 16, 1287 (1983).

7. P. Cukor and M. Rubner, J. Polym. Sci., Polym. Phys. Ed., 18, 909 (1980).

8. T. Higashimura, Y.-X. Deng, and T. Masuda, Macromolecules, 15, 234 (1982).

9. T. Masuda, Y. Okano, Y. Kuwane, and T. Higashimura, Polym. J., 12, 907 (1980).

10. T. Masuda, T. Takahashi, and T. Higashimura, $J$. Chem. Soc., Chem. Commun., 1297 (1982).

11. T. Masuda, Y. Kuwane, and T. Higashimura, $J$. Polym. Sci., Polym. Chem. Ed., 20, 1043 (1982).

12. L. A. Wall and D. W. Brown, J. Phys. Chem., 61, 129 (1957).

13. S. Okamura, Y. Oishi, and S. Ijichi, Isotopes Radiat., 2, 392 (1959).

14. A. R. Schultz, P. I. Roth, and J. M. Berge, J. Polym. Sci., A, 1, 1651 (1963).

15. C. David, D. Fuld, and G. Geuskens, Makromol. Chem., 139, 269 (1970).

16. P. Alexander, R. M. Black, and A. Charlesby, Proc. R. Soc., London, Ser. A, 232, 31 (1955).

17. J. Dannon, J. Chim. Phys., 62, 281 (1965).

18. D. T. Turner, J. Polym. Sci., A, 2, 1699 (1964). 